Rev. Sociedad \& Equidad N 3, Enero de 2012.

\title{
Cuerpo y subjetividad en el gobierno institucional del encierro juvenil
}

SOCIEDADEEQUIDAD

\author{
Body and subjectivity in the institutional \\ governance of youth confinement
}

\begin{tabular}{ll}
\hline Nombre: & Ana Laura López $\left(^{1}\right)$ \\
Filiación: & Universidad de Buenos Aires \\
País: & Argentina \\
Correo: & ana4655@yahoo.com.ar
\end{tabular}

\section{RESUMEN}

En este trabajo se analizan los discursos y las prácticas institucionales que moldean la intervención sobre adolescentes detenidos por causas penales en un centro de privación de libertad en Argentina durante el año 2009. Se trata de un abordaje cualitativo a partir de fuentes secundarias (reglamentaciones y normativas) y fuentes primarias (entrevistas a jóvenes y personal institucional y registros de campo de observación no participante). El objetivo fue caracterizar el despliegue de las prácticas institucionales que estructuran la pena privativa de libertad a partir de 3 dimensiones: los rituales institucionales, la gestión de los cuerpos y la construcción de subjetividades. Una de las principales conclusiones señala que allí se promueve un modelo de pedagogía de la subordinación, a través de la prevalencia de medidas de seguridad asociadas a la "peligrosidad" de los jóvenes, que limita sustancialmente los preceptos protectorios y educativos que legitiman formalmente el uso de medidas privativas de libertad. El análisis del modelo emergente en la gestión del encierro (principalmente a partir de la implementación de legislación acorde al modelo de Protección Integral de Derechos) aporta elementos relevantes para debatir el vínculo del sistema penal con los derechos humanos en general y de niños y adolescentes en particular.

\footnotetext{
${ }^{1}$ La autora es Socióloga, Magíster en Investigación y doctoranda en Ciencias Sociales de la Universidad de Buenos Aires. Es investigadora del Instituto Gino Germani, de la Universidad de Buenos Aires. Sus líneas de investigación son: sociología del sistema penal, específicamente sobre niños y adolescentes.
} 


\title{
S\&e \\ SOCIEDADEEQUIDAD
}

\begin{abstract}
In this paper we analyze the discourses and institutional practices that shape the intervention on adolescents detained for criminal cases in a detention center in Argentina in 2009. This is a qualitative approach from secondary sources (rules and regulations) and primary sources (interviews young people and institutional personnel and field records participant observation). The objective was to characterize the deployment of institutional practices that structure imprisonment from 3 dimensions: institutional rituals, managing the construction of bodies and subjectivities. One of the main conclusions is that it promotes a model of pedagogy of subordination, through the prevalence of security measures associated with the "danger" of young people, substantially limiting protection and educational precepts formally legitimize the use of custodial of freedom. The analysis of the emerging model in the management of confinement (primarily from the implementation of legislation according to the model of Integral Protection of Rights) provides relevant elements for debate on the penal system link with human rights in general and children and adolescents in particular.
\end{abstract}

PALABRAS CLAVES: Adolescentes, encierro, penal, cuerpo, subjetividad.

KEYWORDS: Teenagers, closure, penal, body, subjectivity.

\section{Presentación y apuntes metodológicos}

Este trabajo propone una lectura exploratoria en dirección a la conformación de dimensiones de análisis sobre los rituales, la gestión de los cuerpos y la configuración del sujeto al encierro, en este caso tomando como referencia empírica un centro de detención para adolescentes con causas penales. Dichas dimensiones se vinculan con características inherentes a las instituciones totales (Goffman, 1961) o instituciones de secuestro legal (Foucault, 1975).

En cuanto a los aspectos metodológicos, se considera que la investigación implica: "salir a un espacio de trabajo [que] presupone prácticas especificas de desplazamiento y una atención concentrada disciplinada" (Clifford, 1991: 72). En este sentido se ha orientado el trabajo de campo que confiere respaldo empírico a estas reflexiones, entendiéndolo como una práctica corporizada, un habitus donde los hechos no resultan objetos unívocos sino que: "son envueltos en una trama antes que recogidos, producidos en relaciones mundanas más que en contextos controlados" (1991: 89). 


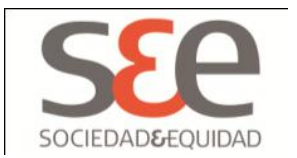

El trabajo se centrará en el análisis intrínseco de caso (Stake, 1999) tomando al "Centro Cerrado Mar del Plata" con el objeto de dar cuenta de las modalidades de gestión institucional sobre las dimensiones de los rituales, la gestión de los cuerpos y la configuración del sujeto al encierro. Se tomó como fuente de datos el reglamento interno (régimen de vida) y el régimen de sanciones para aplicar la técnica de análisis documental (Valle, 2001) y como fuente principal el registro de campo confeccionado durante la visita al Centro, en tanto técnica de observación no participante (Taylor y Bogdan, 1986). Éste ha sido obtenido en ocasión de acompañar una de las inspecciones del Comité contra la Tortura de la Comisión Provincial por la Memoria en el marco de sus tareas de monitoreo de lugares de detención.

El "Centro Cerrado Mar del Plata" se emplaza desde 2005 en el mismo predio que un complejo penitenciario con tres unidades penales de adultos a unos $15 \mathrm{~km}$. de la ciudad, en una zona rural. Resulta contundente la arquitectura penal del mismo, que replica fielmente el diseño de las celdas y estructura de pabellones de las unidades de adultos. Tiene capacidad máxima para 24 adolescentes en 2 módulos para 12 jóvenes cada uno, distribuidos en celdas individuales, denominadas por las autoridades como "habitaciones".

\section{El gobierno en las instituciones totales: claves del ejercicio del poder de castigar}

El análisis propuesto posa la mirada en la noción de despliegue real del castigo (Daroqui, 2001), es decir, en el devenir de la praxis institucional más allá de la mirada jurídica o normativa. Por ello, entendemos el concepto de castigo como una "función social compleja" (Foucault, 1975) o, al decir de Garland (1999), un auténtico "artefacto cultural y social". En este sentido, se ahondará en el entramado de discursos y prácticas institucionales del dispositivo de privación de libertad seleccionado, que representa -en su modalidad de máxima seguridad- el último y más agudo eslabón de la cadena de control socio-penal. Al referir al "entramado" suponemos profundizar analíticamente a través del sutil ( $\mathrm{y}$ a veces no tan sutil) punto de fisura que se produce en la yuxtaposición de los discursos y las prácticas institucionales, que delatan la tensión inmanente y constitutiva de toda institución de secuestro; en especial para aquéllas diseñadas para niños y adolescentes, donde el "deber" técnico-legal de carácter socioeducativo se tensa con "otro deber" de gobernabilidad securitaria intramuros en el marco de sociedades excluyentes (Svampa, 2006) moldeadas mediáticamente por nociones de peligrosidad -especialmente dedicadas a los más jóvenes- que reactivan con recurrencia los principios positivistas de defensa social (Pavarini, 2002) como sustento para las demandas de más sistema penal, castigo y segregación.

Ahora bien, el despliegue real del castigo tiene como noción estructurante la gobernabilidad institucional, concepto en el que se tomará como referencia a Foucault (1991) quien establece que para el análisis de una institución existen tres 


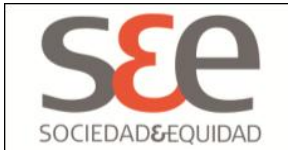

elementos centrales: 1) su racionalidad o finalidad (los objetivos que propone y los medios que dispone para conseguirlos: el programa formal de la institución); 2) los efectos (que pocas veces coinciden con la finalidad); 3 ) el uso (no previsto pero producto del efecto, aunque comporta un sentido y una utilidad a la institución). A partir de estas categorías, la institución será abordada en términos de dispositivo, entendiendo por tal un conjunto heterogéneo de discursos, prácticas, leyes, reglamentaciones, procedimientos, medidas administrativas, instalaciones arquitectónicas y diseños institucionales que conforman una "red" entre "lo dicho" y lo "no dicho", posible a través de una racionalidad y una estrategia de relaciones de fuerza que soportan y son soportadas por un tipo específico de saber.

Dicha gobernabilidad se ejerce a través de un "programa" institucional, resultado de discursos y prácticas que conforman un espacio practicado (Certeau, 1996) y producido por tecnologías de poder. Estos mecanismos y tácticas se establecen en el despliegue biopolítico -en sus diversas expresiones de soberanía, disciplina y seguridad- de ejercicios de poder sobre la vida, entendiendo por ello al cuerpo-individuo (anatomopolítica) como un privilegiado blanco en el continnum disciplinario; suerte de máquina a la cual es preciso educar, docilizar, moldear y adiestrar para una correcta re-adaptación, recuperación y/o re-socialización, en base a un riguroso cálculo del tiempo, los espacios y movimientos, y su pedagógica vigilancia. En este sentido: “(...) la prisión -mera privación de la libertad- no ha funcionado jamás sin cierto suplemento punitivo que concierne al cuerpo mismo (...) ha procurado siempre cierta medida de sufrimiento corporal" (Foucault, 1975: 23).

El encierro como dispositivo de poder se expresa en el cuerpo, imprimiendo un régimen o "programa" institucional que implica un particular modo de construcción de subjetividad (Foucault, 1975) emplazado en una institución total caracterizada por la absoluta regimentación de la vida (Goffman, 1961). El diseño de una institución total supone un determinado perfil de sujeto, que moldea a través de sus prácticas e impone normas de regulación corporal y subjetiva en el marco de las específicas relaciones de poder que allí se traman y determinan "estructuras de sentimiento" (Ortner, 2005: 29), esto es, modos regularizados de constitución subjetiva y significación social. Dichas intervenciones se sirven de técnicas disciplinarias como el cercenamiento espacial, la división de zonas y su jerarquización en accesos y permanencias, el control de las inconductas, la vigilancia, el despojo de un sinfín de objetos etiquetados como "no autorizados" y el establecimiento de accesos diferenciados bajo el modelo de la regla de convivencia como instrumento de coerción, que despliega al interior de la penalidad misma del encierro otras micropenalidades o suplementos punitivos a la privación de libertad. En este sentido, retomamos la idea del cuerpo como una pura producción social (Le Breton, 1995) en el marco del desarrollo de una medida judicial penal. 


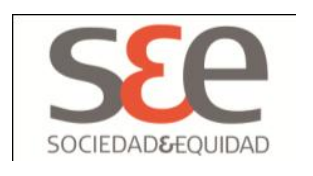

El paso de un adolescente por estas instituciones provoca marcas, es decir, inscripciones que tipifican, categorizan y establecen líneas de circunscripción, definen a quienes allí se penaliza como un colectivo problemático, un "otro" claramente identificado sobre el cual se requiere desplegar estrategias específicas durante la vida en el encierro ${ }^{2}$. Como explican Bianchi y Portillo, dicha regulación y vigilancia inherente a las instituciones totales demarcan efectos de poder sobre el tiempo y el espacio que "en virtud de dicha experiencia de encierro adquieren un contenido y un sentido específicos para las adolescentes, y que tienen una vital importancia en la construcción y en la concepción de tales categorías, dado que constituyen una referencia ineludible al momento de pensarse y pensar su propia trayectoria vital" (Bianchi y Portillo, 2007: 5).

Así, en este tipo de dispositivos se desarticula el dominio de los sujetos sobre su propia economía de acción, bajo la égida de un régimen de minucioso control y estipulación de tiempos y espacios por los que puede circularse, actividades permitidas y prohibidas bajo sanciones y "beneficios" que se erigen como herramientas para la gobernabilidad intramuros. Esta desarticulación del dominio de los sujetos provoca un cambio en el registro de la subjetividad y aloja la generación de un habitus específico de la vida en el encierro. El habitus es un sistema de disposiciones duraderas que confieren sentido al mundo social siendo simultáneamente estructuradas y estructurantes, a la vez que "define y activa una forma específica de interés, una ilusión específica como reconocimiento tácito del valor de las apuestas propuestas en el juego y como dominio práctico de las reglas que lo rige" (Bourdieu, 1995: 80). Así, la dinámica institucional, tanto para los trabajadores como para los adolescentes detenidos, se nutre en ambos casos de un habitus pre-adquirido (con circuitos, ritos y modalidades en algunos aspectos divergentes y en otros no) sobre el cual toma sentido la práctica pero que, sin embargo, se crea y recrea permanentemente a modo de estructura estructurante.

\section{Cuando el discurso jurídico invisibiliza al castigo penal}

El problema del castigo ha sido abordado -en las ciencias sociales y jurídicas- desde diversas perspectivas, enfoques y recortes, que sin dudas establecen miradas diversas sobre el "objeto" que construyen. Así, podrían identificarse -sin arreglo a rigurosidad exhaustiva- dos grandes líneas de reflexión: aquéllas que se concentran en el "por qué" (las causas o etiología) de la comisión de actos que infringen el sistema normativo establecido en determinada época y sus consecuentes interrogaciones acerca de la intervención necesaria para prevenir, reprimir o corregir a los sujetos involucrados. En sus antípodas, otras corrientes que señalan la necesidad de hacer

2 "Instituir es consagrar, es decir, sancionar y santificar un estado de cosas, un orden establecido, como hace justamente una constitución en el sentido jurídico-político del término" (Bourdieu, 1985: 80). 


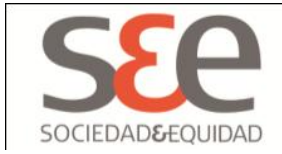

visible la conformación de dispositivos, prácticas discursivas y formas de intervenir sobre aquellos sujetos seleccionados por los mecanismos de control social penal en el despliegue de sus agencias, sean éstas la policía, el poder judicial o -en su última expresión- las instituciones penales. Dicha mirada, asociada a las corrientes "críticas", posa su atención en el ejercicio de la violencia institucional y los modos de intervención y construcción de sus sujetos-objetos.

A veces ambas líneas se confrontan, yuxtaponen y por fin anulan como resultado de la esterilidad de contraponer miradas y recortes analítico-problemáticos claramente diferentes. Así, frente a la denuncia de condiciones degradantes de detención parecería ser justificada su morigeración en pos de una mejor "rehabilitación" de los sujetos atravesados por dichas condiciones estructurales del sistema penal, que bajo la primera mirada son concebidas como situaciones anómalas o fallidas (y no constitutivas). Este trabajo sostendrá que dicha oposición resulta engañosa en tanto -a modo de una falacia ecológica de confusión de niveles- hace difusa la tensión entre los fines y efectos de la pena sobre los sujetos de ella destinatarios y sobre el cuerpo social en general. En otras palabras: los debates que se traman a partir del "efecto espejado" entre institución e instituido, apelando a la escasa "eficacia" del sistema penal, desdibujan con miopía analítica las características que asume la configuración institucional del castigo como parte de un contexto socio histórico determinado y bajo procesos sociales más amplios, con sus propias funcionalidades y efectos. En esta línea, se entiende al sistema penal desde la corriente de la economía política de la penalidad, que sostiene que es necesario despojar a las: "instituciones sociales dedicadas a la ejecución de las penas, de sus velos ideológicos y apariencias jurídicas y describirlas en sus relaciones reales (...) la pena como tal no existe; existen solamente sistemas punitivos concretos y prácticas determinadas para el tratamiento de los criminales" (Rusche y Kirchheimer, 1984: $3)$.

Prescindir de la ecuación sobre la eficacia "educativa" de la intervención sobre los sujetos (en términos de represión de futuras acciones delictivas) permitirá entonces avanzar sobre otras preguntas de interés para el campo de las ciencias sociales y especialmente para la agenda actual de los derechos humanos, por ejemplo: ¿Cómo se piensa la función e intervención de los institutos penales para niños/as y adolescentes en la actualidad? ¿Cómo se despliegan las modalidades de gestión institucional sobre dichos cuerpos? ¿Qué discursos, prácticas y sujetos "produce" la pena privativa de libertad para los más jóvenes? ¿Qué rituales y habitus atraviesan a los agentes de dicho campo?

Para ello, en lo subsiguiente se prescindirá del "discurso jurídico" para atender la comprensión de los sentidos (explícitos e implícitos) que estructuran este despliegue; de los discursos que exhiben y de las "maneras de hacer" que se ritualizan en el más cruento recurso del sistema penal juvenil: la privación de 


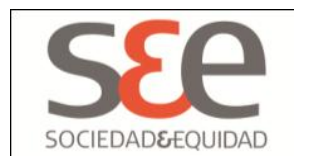

libertad. Desde esta perspectiva, es dable sostener que la "confusión estratégica" entre fines declarados-efectos producidos y la pretendida eficiencia de la intervención penal es especialmente notable en el caso de las personas menores de edad con causas penales.

En otras palabras, desde los discursos institucionales, las "disfuncionalidades" de los centros cerrados suelen circunscribirse a un funcionamiento deficiente "coyuntural", que de algún modo invisibiliza el encierro como un ejercicio del poder de castigar, naturalizado en la trascendental y -por veces mesiánica- misión de "educar”, “contener" y demás eufemismos que en-cubren la coacción del encierro y la naturalizan en sus habitus como una medida necesaria: "La trampa de la razón pedagógica consiste precisamente en que arrebata lo esencial aparentando que exige lo insignificante, como el respeto a las formas y las formas de respeto que constituyen la manifestación más visible y, al mismo tiempo, mas "natural" de la sumisión al orden establecido" (Bourdieu, 1991: 119).

Antes de avanzar en el análisis del caso empírico, se sostendrá como supuesto de trabajo que la imbricación de los nuevos y viejos discursos y prácticas en la producción de un dispositivo seguritario-penal, así como las modulaciones programáticas se orientan hacia la conformación de cuerpos-excluidos, neutralizados y des-subjetivados, en el contexto de programas de gobernabilidad institucional enunciados desde anclajes afectivos-protectorios pero con notables efectos de incapacitación selectiva sobre dichos sujetos.

\section{Contexto legislativo y cambios en la relación Estado-niñez}

Tanto en Argentina ${ }^{3}$ como en el resto de América Latina, hace ya varias décadas comenzó un proceso de reformulación de la histórica relación entre el mundo adulto e infantil, arraigada en el modelo del "Patronato" o la tutela judicial de corte protopaternalista, que bajo la díada compasión-represión (Daroqui y Guemureman, 2001) disponía de la patria potestad en forma relativamente indistinta sobre niños víctimas de delitos y niños acusados de cometerlos. Actualmente existe una amplia y hegemónica mirada que desacredita los principios de dicho modelo tutelar, aquel que signó durante un siglo la forma de pensar a los niños "menores" y el diseño de las

\footnotetext{
${ }^{3}$ Argentina ratificó la Convención por los Derechos del Niño en 1990 y la incorporó a su Constitución Nacional en el año 2004 junto a otros tantos tratados internacionales (Art. 75, inc. 22). Recién en el año 2005 se derogó la ley tutelar (10.903) y se sancionó la Ley Nacional 26.061 de Promoción y Protección de Derechos de Niños, Niñas y Adolescentes. Al año 2011 pervive el Régimen Penal de la Minoridad (Decreto 22.278) que es la ley penal juvenil de fondo (por el sistema federal existen normativas nacionales de fondo y provinciales de procedimiento) de corte tutelar. La mayor parte de las provincias adhirieron a la ley $26.601 \mathrm{o}$ cuentan con legislación local propia y acorde al modelo de protección integral. Solo unas pocas cuentan con ley de procedimiento penal juvenil ajustada a la protección integral, entre ellas la Prov. de Bs. As.
} 


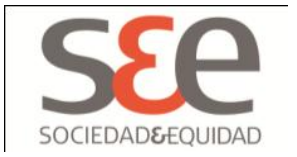

instituciones creadas para "proteger" a aquellos "en riesgo moral y material" que en definitiva eran los niños y familias que no cumplían con las pautas de normalización que se desplegaran desde fines del siglo XIX como ejes de la construcción de un orden social post migraciones, anclado en la necesidad de las elites dominantes de consolidar el Estado nación moderno. En esta matriz se ejerció la internación segregativa tanto para causas "asistenciales" como "penales" en una indistinción profusamente criticada.

En el plano discursivo y sobre la legislación específica, la Provincia de Buenos Aires (donde se emplaza el Centro Cerrado Mar del Plata) transitó un prolongado y complejo proceso de transformación legislativa (López, 2010), aunque actualmente puede sostenerse que es una jurisdicción con un encuadre normativo (Ley 13.298 y 13.634) acorde a la mayoría de los lineamientos de la Convención de los Derechos del Niño. Desde la década de los '90 dicha Convención se erigen como línea teóricojurídica sobre las que se estima deseable -y obligación por parte de los Estados que suscriben a los mismos, tal como es el caso de Argentina- organizar el andamiaje legal e institucional destinado a los más jóvenes, estableciendo la noción de niño como "sujeto de derecho" y dotándolo de las garantías procesales del derecho penal moderno, más un plus de garantías procesales (plazos acotados, múltiples tipos de medidas y principio amplio de oportunidades recursivas, principio de flexibilidad y prioridad de la resolución alternativa al conflicto e interpretación amplia de la aplicación del perdón judicial/sobreseimiento por principio de oportunidad) conferidas en consideración de su condición de sujeto en desarrollo.

A continuación comenzará el desarrollo de la primera dimensión de análisis sobre el caso seleccionado, referida a los rituales institucionales.

\section{Los rituales institucionales}

Para el abordaje del caso seleccionado y en particular del "programa" institucional, es necesario entender sus dinámicas a partir de prácticas rituales. Si las prácticas y las representaciones rituales son prácticamente coherentes, es porque son el producto del funcionamiento combinatorio de un pequeño número de principios generadores unidos por unas relaciones que las hacen susceptibles de ser sustituidas en la práctica, es decir, que son capaces de producir resultados equivalentes en diferentes situaciones desde el punto de vista de las exigencias "lógicas" de esa práctica (Bourdieu, 1991: 159).

Los ritos tienen por función social el separar e instituir diferencias que se naturalizarán con la eficiencia simbólica del propio rito. Instituye así una diferencia que se torna constante en el orden social y sobre la que se montan prácticas, comportamientos, gestualidades, expectativas y representaciones en función de los roles que establecen determinadas formas del "ser". 


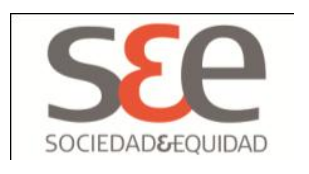

El ingreso de un adolescente a este tipo de instituciones se consagra a través de un rito de institución específico que, instrumentados por sus agentes sociales (trabajadores, directivos, profesionales, etc.) asigna propiedades de "naturaleza social" -tal como la organización de la vida intramuros- que se confunden con "naturaleza natural". Así, la separación que opera el ritual de institución termina por ser un efecto de consagración. Si instituir es asignar una esencia o competencia, un deber ser o derecho a ser es "significar" a alguien y a sus conductas: "La esencia social es el conjunto de esos atributos y esas atribuciones sociales que producen el acto de institución como acto solemne de categorización que tiende a producir lo que designa (...) es un acto de comunicación” (Bourdieu, 1985: 81). Otorga significado y notifica autoridad y deberes estatutarios, siendo este condicionamiento de la conducta el verdadero efecto del ritual, su "magia performativa". La función de estas fronteras mágicas es evitar su cruce, no solo de los agentes externos a la misma sino principalmente de los internos, que deben actuar en consecuencia y generando una "segunda naturaleza" que se imprime en este caso sobre los sujetos al encierro.

Uno de los tópicos indagados en tanto prácticas rituales de institución es el "régimen de vida", es decir, la documentación que norma y estipula formalmente los modos de organización institucional para los adolescentes allí detenidos. En el mismo se detalla una exhaustiva grilla horaria que demarca tiempos, espacios y tareas que deben realizar los adolescentes desde el denominado "levante" hasta el "acueste", definiendo una minuciosa microfísica de las conductas. Así, el "régimen de vida" puede ser comprendido como un ritual que, en el ingreso a la institución es "enseñado" por los celadores, quienes definen este período como "de ablande", y que consta de un encierro prolongado (aislamiento en celda) inicial de 6 días, para que el adolescente "comprenda" las pautas de supervivencia y logre establecer un vínculo no confortativo con el resto del grupo, según lo expresado por estos actores durante las entrevistas, adaptándose a las rígidas normas que cronometran el día en el encierro ${ }^{4}$.

\footnotetext{
${ }^{4}$ El período de duración del encierro al ingreso no está explícitamente mencionado en el régimen de vida, lo cual es lógico puesto que este documento solo estipula las actividades programáticas para un día promedio de un detenido (que aquí no se reproduce por cuestiones de extensión). Sin embargo, esta práctica es explícitamente referida como parte de la organización institucional por el Director del establecimiento en la entrevista realizada. En este sentido, es una práctica que aun sin estar escrita (de por si es escasa la producción de este tipo en el ámbito de la Subsecretaría de Niñez y Adolescencia de la Provincia de Buenos Aires) es parte formal de los lineamientos institucionales de ésta y otras de igual características sobre las que se ha efectuado trabajo de campo y que no han sido analizadas en este artículo.
} 


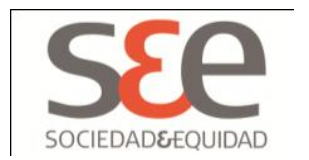

\section{El cuerpo}

A partir de la descripción del "régimen de vida", se propone reflexionar sobre el "lugar y modo" que se le asigna al cuerpo adolescente en esta programática. Por ello se entiende que el cuerpo: "es un dato socializado, semantizado" (Le Breton, 2002: 152). Según Douglas, todo cuerpo expresa una dimensión de lo social a la vez que el control corporal constituye una expresión del control social: "El sistema social impone un control y por lo tanto unas limitaciones a la utilización del cuerpo como modo de expresión (...) a un control social fuerte corresponde un control corporal igualmente estricto" (1973: 91-96).

Se trata de cuerpos semantizados y regimentados en un continnum disciplinario-securitario orientado a la obediencia-desactivación, principios de regulación que encuadran en la lógica penal de las sociedades de la excedencia social (De Giorgi, 2006). Así: "el cuerpo designa no solo la posición actual, sino también la trayectoria” (Bourdieu, 1986: 184). Antes que “cualquier” cuerpo adolescente, el régimen institucional construye un cuerpo sujeto al encierro que se moldea en una estricta disposición de horarios y "habilitaciones" estipuladas (cantidad y tipo de días para afeitarse, uso permitido del DVD, exigencia de mantener pelo y uñas cortos, uso de uniforme permanente y también en caso de compartir una visita ajena, horarios de baño, elementos prohibidos, requisas con desnudo total y flexiones, exhibición de genitales y encías, prohibición de usar aros y elementos estéticos, etc.) que dan cuenta de una disposición casi absoluta sobre las corporalidades, tanto desde su capacidad de desplazamiento y acción así como la regimentación de su estética y la permanente posibilidad de ser cuerpos vigilados, explorados y requisados. Los horarios y pautas señalan una uniformidad rutinaria que se empalma con un régimen de disciplinamiento que pretende imprimir sobre estos sujetos modos de disposición del tiempo y del cuerpo previsibles y pautados, moldeando conductas a través de la norma y la autoridad como eje de organización.

A través de la mirada y del discurso de los otros el cuerpo es: "un producto social que debe sus propiedades distintivas a sus condiciones sociales de producción" (Bourdieu, 1986: 186). Así, la previsión de lo permitido y lo no permitido resulta minuciosamente demarcada, en tanto posibilidad de desplazamiento y acción. En caso de no cumplir con las pautas o frente a un conflicto (entre pares o hacia celadores o directivos), la institución establece un "Régimen disciplinario" que define las sanciones, es decir, el castigo dentro del castigo. El mismo estipula: "El objetivo de este orden disciplinario en un establecimiento de régimen cerrado, capacitado para albergar a jóvenes en conflicto con la ley penal, intenta contribuir a la seguridad y a una vida comunitaria ordenada, y ser compatible con el respeto de la dignidad inherente del joven". Como medida sancionatoria tipifica: "Dar a conocer al personal del Establecimiento que las medidas disciplinarias deben ser aplicadas a partir de las transgresiones de mayor gravedad y esas derivan en la 


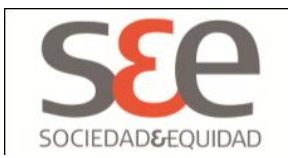

restricción de las actividades recreativas grupales y no deberán superar los 10 (diez) días. Al día 5 (cinco), del cumplimiento de la sanción y de acuerdo al comportamiento del joven podrá participar de una hora por día de las actividades recreativas, hasta finalizar su sanción. Este Régimen de cumplimiento debe ir acompañado de un compromiso establecido con el joven, donde se le enseñe que si comete una nueva falta vuelve a iniciar el proceso desde el comienzo" (el resaltado es propio).

La sanción consta de medidas de aislamiento prolongado (permanecer sin salir de la celda, donde no se permite tener objetos más que la muda de ropa y alguna foto $)^{5}$. Asimismo, establece que: "la sanción será considerada siempre un instrumento de Educación y un medio de promover el respeto del joven por sí mismo, como preparación para su reinserción en la comunidad" (el resaltado es propio). Así, el castigo dentro del castigo (o los "suplementos punitivos" al decir de Foucault) aún bajo enunciados educativos, se concentra en el aislamiento como técnica de dominio, donde el cuerpo sigue siendo blanco privilegiado de la ejecución de la sanción, a través de su cercenamiento espacial y la exacerbación de los límites sobre la economía de la acción. La posibilidad de permanecer en el grupo por un período de tiempo constituye una sanción "educativa" que ancla centralmente sobre lo corporal: "Y no acabaríamos de enumerar los valores hechos cuerpo, mediante la transubstanciación que efectúa la persuasión clandestina de una pedagogía implícita, capaz de inculcar toda una cosmología, una ética, una metafísica, una política, a través de exhortaciones tan insignificantes como "mantente derecho" (Bourdieu, 1991: 118).

En los Registros de Campo hemos relevado: "el celador comenta que las sanciones van de los 5 hasta los 10 días. Constan del "engome" (encierro todo el día) y bajar la cantidad de cigarrillos diarios a 3 (...) Un chico sancionado dice que no firmó ningún parte por escrito de la sanción y que la duración de la misma la decide en cada caso el jefe de piso. Cuenta que si al estar sancionado patean la puerta les "agregan" 5 días más de sanción a la ya impuesta, que pueden llegar a 1 mes (...) Mauro está sancionado por pelearse con otro chico. Dice que tuvo antes otra sanción de 3 días por "discutir y gritar" desde adentro de la celda porque el celador no le prestaba atención y la de ahora de 5 días por pelear. Estuvo 2 meses en el otro pabellón y se cambió a este "para hacer conducta". La ventana no tiene vidrio (es invierno y hace mucho frío). Tiene una sola muda de ropa (la puesta). Como el resto, no tiene zapatillas, sino

\footnotetext{
${ }^{5}$ El reglamento estipula: "las medidas disciplinarias (...) derivan en la restricción de las actividades recreativas grupales", lo cual en la práctica y según lo constatado durante la visita al Centro y las entrevistas a los trabajadores y jóvenes, la sanción se traduce en permanecer en la celda sin realizar actividades durante el período por el que se fije la sanción.
} 


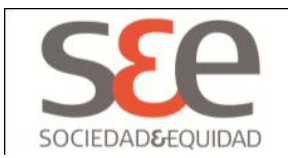

ojotas con medias. Dice que no le dieron el reglamento por escrito, pero que él "ya sabía cómo era la cosa, porque ya había estado antes acá". Sale 6 hs. por día de la celda en los 2 recreos (en el que se incluye el tiempo de asistencia a clase), hace 3 meses que va a la escuela, pero ahora que está sancionado no lo llevan, que "a veces" va al taller de computación y de ética, pero no mientras esté sancionado." (Registro de Campo)

Avanzando en la indagación sobre la organización del dispositivo institucional, un primer interrogante es el criterio de distribución espacial de los cuerpos:

"Según el Director, los módulos no tienen ninguna clasificación según la población que aloja. Aunque indagando esta cuestión con los adolescentes no se ha encontrado un patrón en común ya que algunos referían a un módulo determinado como de "conducta" y otros definían al mismo como "cachivache" [referido a mala conducta]. Se puede suponer que la organización de las celdas y los adolescentes se ajusta a criterio de gobierno sobre situaciones individuales, modulando el paso de unos y otros según coyunturas específicas." (Registro de Campo)

Del extracto de campo anterior se deduce que el alojamiento se define en función de meras coyunturas de gobierno intramuros, en el mantenimiento de la "seguridad", sin duda una de las premisas fundamentales del discurso de los trabajadores de la institución.

En síntesis, los cuerpos adolescentes encuentran una rígida matriz de movimientos permitidos y previamente calculados, que aun sin reproducirse de forma absolutamente lineal respecto del reglamento institucional formal, sí logran establecer corporalidades socialmente producidas en el marco del encierro penal, asumido por categorías de control espacial y corporal específicas, orientadas a un control de la economía de movimiento de los cuerpos, control centralizado en los celadores como principales agentes que ejercen el poder de vigilar y encerrar.

\section{Sujetos al encierro}

El programa institucional propone la construcción de un determinado sujeto al encierro. Al indagar con los jóvenes sobre el transcurrir de la vida intramuros, la principal característica son las más que prolongadas horas "sin nada para hacer", tal como puede observarse en uno de los Registros de Campo:

“Lo llamativo es que no les permiten tener ningún objeto personal, ni siquiera su propia ropa, que solo pueden utilizarla los días de visita, al igual que las zapatillas ("por su seguridad y para evitar peleas y robos entre ellos" me dice el celador, luego el director nos dirá: "El día de visita se visten con su ropa, que nosotros se la lavamos y guardamos"). El extremo de medidas que toman para evitar las autoflagelaciones en los adolescentes o para los conflictos 


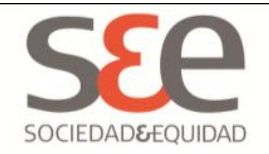

propios de la convivencia en estos espacios, llegan al extremo de una total despersonalización y desubjetivización. "Ningún objeto, nada para hacer" pareciera ser la propuesta lúdica de la celda-dormitorio terminando por devastar el ya desnutrido orden de lo simbólico para estos adolescentes. Pero, según los celadores, así están "seguros". Las celdas están completamente "peladas", los jóvenes no tienen ningún objeto para transcurrir el tiempo de "engome", que asciende a 18 horas diarias. Están sin nada para hacer ni para ver. Los sentidos, los ojos, las manos y las piernas carecen de funcionalidad en este cubículo. La despersonalización en las celdas es impactante, no cuentan con ninguna marca singular. Usan la ropa provista por el instituto (jogging de frizza verde o bermudas, muchas de estas prendas rotas o deshilachadas, que nunca son las mismas ya que los lavan y les puede tocar cualquier conjunto). Una toalla blanca y dos pares de medias que ellos deben lavar. Los únicos objetos permitidos por celda es un secador de piso de goma "chiquito" $(25 \mathrm{~cm})$ con un palo "recortado" a unos $30 \mathrm{~cm}$. Es realmente muy cortito; parece un instrumento de limpieza de juguete. Las celdas solo tienen por iluminación una lamparita de bajo consumo que es extremadamente escasa. Aun cuando no tienen nada para leer ni hacer, lo tenue de la luz resulta muy molesto para la vista; genera una sensación de pesadez y oscuridad muy molesta. Durante el día les quitan el colchón y las frazadas, y no pueden apoyarse ni recostarse en ningún lugar que no sea la chapa fría del camastro o el piso y banco de cemento, que también estaba muy frío." (Registro de Campo)

Cada adolescente -si no está sancionado- accede a dos salidas a "recreación" (que es simplemente el acceso a un salón comedor pequeño con mesas y bancos de cemento y una TV y DVD) que dura unas 3 horas cada una. Estas salidas, dentro de las que se incluye $1,30 \mathrm{~h}$. de escuela diaria (en caso de acceder a la misma) son los únicos momentos de "desengome" (estar fuera de la celda). El resto del largo día transcurre en celdas mínimas, sin el colchón (se los retiran durante el día) y sin ningún objeto que les permita realizar actividades. Es abiertamente un encierro segregativo "a la espera de la nada", donde se maximizan las medidas de pura "seguridad", que rayan la neutralización subjetiva:

"Voy hacia otra celda. El subdirector me "intercepta" en el medio para explicarme que por seguridad no nos pueden abrir más de una celda a la vez, me reitera que es "por seguridad". Le digo que está ok, que por favor me abra otra. Paso sola a la celda del otro chico que está sancionado. Tiene 17 años. Al principio no quería hablar con nosotros, pero al volver aceptó conversar. Cuando me asomé por la mirilla de la puerta a charlar con él lo vi sentado en el camastro de metal, sobre el chapón (sin colchón), encorvado, con las manos pequeñas- sobre las rodillas y la cabeza gacha. Tiene mucha cara de tristeza. Por la mirilla su silueta se dibujaba a contraluz de la ventana; una silueta de un cuerpo adolescente encorvado, despojado y triste, a la espera de la nada. 


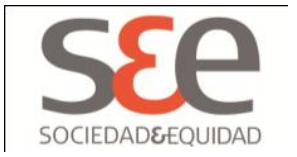

Esa imagen y sensación no se me olvidan. Durante el resto de la conversación estuvo cabizbajo y triste. Le pregunté si se sentía triste. Me dijo que no, que estaba muy bien ahí, que no precisaba nada. Estaba como vencido, desganado. La mayor parte del tiempo se quedó encorvado mirando al piso. Todos los entrevistados dicen que ahí están bien, no cuestionan nada y comparan su situación con la de un penal de adultos para opinar que "están bien". (Registro de Campo - Ver ilustración en Anexo)

Así, el habitus elaborado, estructurado y estructurante a partir de la práctica institucional de los agentes, conforma un perfil de "producción subjetiva" definido y orientado en sentido de la permanente imposibilidad del acontecimiento no previsto, cercenando cualquier atisbo de singularidad o autonomía subjetiva sobre el molde de gestión intramuros que se instala. No obstante, antes que pretender el disciplinamiento y docilización de los adolescentes en términos foucaultianos clásicos, desde la perspectiva de los actores prima la idea de "mantener el orden" sin exhibirse -al menos abiertamente- fuertes máximas del discurso resocializador, sino la necesidad de garantizar la contención físico-espacial ("seguridad") de los cuerpos "a cargo", para lo cual este modelo de gobernabilidad resulta, desde el habitus de los celadores, un modelo eficaz y necesario.

"Llamativamente el Director refiere a las celdas como "dormitorios", ingenuidad máxima la mía ya que al tener la entrevista con el Director antes de conocer el pabellón, éste refería todo el tiempo a los "dormitorios", su buen estado de conservación y pulcritud, creyéndome entonces que se trataba de habitaciones similares a una casa, con camas y cierto mobiliario, objetos, etc. Al ver los "dormitorios" comprendí mi ingenuidad frente al discurso del Director ya que las celdas son sencillamente celdas, desprovistas de cualquier característica que la asemeje a un "dormitorio" y con exactamente los mismos modelos y elementos de construcción (sanitario, bacha de aseo, camastro) que las unidades de adultos visitadas con anterioridad. El uso de eufemismos será una constante durante toda la visita. Además de los "dormitorios" (celdas) se refieren a "recreación" para la salida de celda, "colegio" al instituto penal, "maestros" para los guardias y "medidas de seguridad" para la neutralización y anulación subjetiva de adolescentes encerrados sin ningún objeto durante 18 horas por día" (Registro de Campo).

Este discurso eufemístico exhala una institución imaginada como parte necesaria de las percepciones que estructuran el hábitus, aunque en poco se asemeja a la institución real, si entendemos por este término a la trama de relaciones de poder y dominación que delimitan las características del dispositivo analizado ${ }^{6}$. En el

\footnotetext{
${ }^{6}$ Los actores del área de "minoridad" refieren a los centros cerrados como "colegios", denominación que se transmite y reaviva en el habitus del Campo y señala la curiosa representación proto-educativa y eufemística en relación a la funcionalidad de castigo
} 


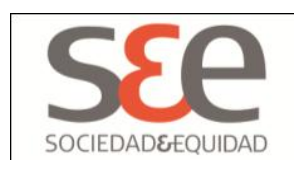

orden de este imaginario es donde los discursos de los actores institucionales traman con la omnipresente noción de la "seguridad", una "retórica del amor" que convalida el encierro:

"El subdirector se apura en aclarar sobre la unidad penal de adultos lindera: "Ellos son penitenciarios, nosotros no, nosotros somos civiles", intentando marcar una vez más alguna diferencia respecto de sus vecinos de "predio" en el complejo del que forman parte. Cada módulo tiene un "jefe" y un "jefe de piso" encargado de los dos módulos: "Nosotros le decimos jefe de piso, no de 'guardia', porque es diferente (...) "Acá los chicos se van y quieren volver, no hay nada afuera. Yo no quiero que estén acá, es una locura que la mayor contención la tengan en el encierro (...) Al pibe si no le das amor no lo vas a recuperar, porque es una cuestión de amor, que el pibe vea una persona mayor que con el ejemplo lo aconseje bien, le dé ejemplo de educación y trabajo pero con lucha, así se puede" (Director)( Registro de Campo).

Luego de este intercambio, comenzó el recorrido por la institución junto con los representantes del organismo de Derechos Humanos con el que se asistió; el registro señala:

"Al ingresar al módulo se ubica la "pecera", que es un cuarto con la parte superior de las paredes de vidrio, suerte de garita de control donde permanecen los asistentes de minoridad (guardias). Allí hay papeles, objetos varios, un escritorio, perchero, silla, termo, etc. Al lado de la pecera hay dos gabinetes, uno para realizar las entrevistas psicológicas y otro donde trabaja el equipo técnico. Desde la pecera se debe atravesar una reja-puerta para acceder al SUM del módulo. Para ello nos piden que dejemos en la pecera nuestras carteras: "Es por su propia seguridad" nos dice el maestro-celador. Aquí comienza un nuevo capítulo de la visita al instituto. Cerrado el capítulo del “amor” proferido por el Director en su oficina, comienza el capítulo de la "seguridad", donde pudimos observar y vivenciar el principio incursionado de un determinado tipo de seguridad que los celadores y el subdirector impartirán durante toda la visita a los adolescentes destinatarios del "amor": dejar las

judicial que cumplen, desde su diseño arquitectónico hasta sus funciones de garantía de privación de libertad involuntaria para autores (o presuntos) de delitos. 


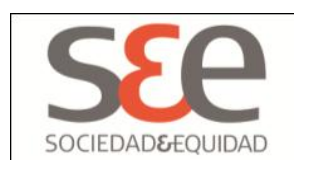

carteras y todo objeto que podía ser robado por los jóvenes, no abrirnos más de una celda "dormitorio" a la vez, no permitirnos estar con la celda abierta o con más de dos celdas mientras haya 5 adolescentes en recreación en el patio, no dejarnos solas con uno de los jóvenes porque -según manifestó el celador frente al propio adolescente- "él es peligroso", justificar la necesidad de mantenerlos sin colchón todo el día, sin zapatillas -solo con ojotas y medias durante el invierno- justificar que no tengan NINGUN objeto en la celda-dormitorio, etc. Por cada una de las ridículas medidas de "seguridad" implementadas el subdirector no se cansaba de decir: "Es por la seguridad de los chicos y de ustedes" (Registro de Campo).

Como detalla el último extracto de campo, en el recorrido posterior a la entrevista con el Director (donde se exhibió una suerte de "institución imaginada" por el discurso afectivo-amoroso) y luego de las entrevistas a solas con los adolescentes, se erige con impactante distancia la "institución real", basada en el régimen del "engome":

“Al ingresar al instituto le tocó, como a todos los demás, la "adaptación de ingreso" que consta de estar 6 días encerrado (engomado) sin salir a ningún lado. Solo le pasaban la comida por el pasaplato. Este es el ritual de “bienvenida y adaptación” institucional. Recién el sexto día después de su llegada lo sacaron de la celda: "Me sacaron para evaluarme, el equipo técnico" (Registro de entrevista con Mauro, 16 años).

"Para acceder a los dormitorios-celdas desde el SUM hay que pasar otra puertareja que se mantiene cerrada con un "gancho" o "sapo" (candado). Al atravesarla se ingresa a un pasillo de aprox. 1,5 mts. de ancho y unos $12 \mathrm{mts}$. de largo. A cada lado del pasillo se ubican 6 celdas-dormitorio numeradas. Cada celda aloja a un adolescente. La puerta es "ciega" (de metal), pintada de gris con un pasaplatos rectangular de unos $10 \times 20 \mathrm{~cm}$. En la parte inferior de la puerta hay otro pasaplato de forma cuadrada de unos $20 \times 20 \mathrm{~cm}$. a la altura del rostro de una persona, la cual se abre y cierra desde afuera, por ello el interior de la celda puede ser observado desde fuera durante todo el día. Las puertas tienen dos pasadores (uno de la construcción original a la altura del picaporte y otro soldado a posteriori de su construcción a la altura de las 


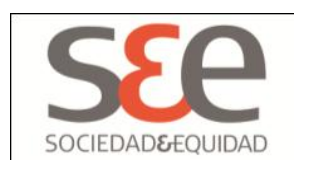

rodillas). El pasador principal está siempre cerrado con el "gancho", salvo cuando los jóvenes están fuera de la celda, en recreación. Comenzamos a pasar a las celdas a conversar con los adolescentes. Los "maestros" (celadores) se negaron a abrir más de una celda a la vez por cuestiones de "seguridad" (paradójicamente el Director había dicho que tiene el personal necesario, pareciera que no o que la lógica de la "seguridad" no permite innovar en la lógica del encierro). Cada celda es de $4 \times 2 \mathrm{~m}$. El único mobiliario es un camastro empotrado al piso (construido con láminas de metal, una mesa y un banquito circular de cemento también fijos al piso y un baño pequeño dispuesto al lado de la mesa (donde se come), sin cerramiento en la puerta y sin luz eléctrica, con una pileta pequeña a modo de lavatorio y una canilla de plástico. Inmediatamente contiguo a la pileta (emplazados en la misma plataforma de cemento) pero a unos $25 \mathrm{~cm}$. más abajo, hay una letrina sin tapa (agujero). Para lavarse las manos o utilizar la bacha la persona debe inclinarse por encima de la letrina, que al no tener tapa emana olor, en muchos casos, nauseabundo" (Registro de Campo).

En la "institución real", las requisas exigen la desnudez, la exhibición del cuerpo en desarrollo en situaciones humillantes:

“Lo requisan cuatro veces por día (a la mañana, al salir a recreación, al volver de recreación y a la noche, al acostarse). La requisa de cuerpo consta de desnudo total, realizar dos flexiones de piernas (agacharse en cuclillas hasta llegar al piso, repetir dos veces, mostrar los genitales frente a dos o más celadores). También debe mostrar la planta de los pies, la boca (encías) metiéndose el dedo y revolverse el pelo. Todo ocurre dentro de la celda frente a 1 o 2 celadores ("maestros"). También requisan la celda en busca de objetos o elementos prohibidos: "Te dan vuelta la celda"(Registro de entrevista con Mauro, 16 años).

El ejercicio de la violencia física complementa el orden de subordinación que marca la cadencia del encierro "menor":

"Al lado de la puerta el "maestro" se queda estratégicamente escuchando la conversación. Le pregunto al chico -en voz baja- sobre golpes, me dice: "Si vos no les pegás ellos no te pegan". Le pregunto si últimamente le han 


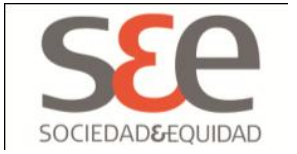

pegado o ha visto que le pegan a alguien. Dice: "Hace un tiempo le pegaron entre 3 maestros a un pibe, le rompieron toda la nariz" (mientras gesticula situación de nariz quebrada-partida) (Registro de entrevista con Emanuel, 17 años).

Estas rutinas y ritos sobre los cuerpos y las subjetividades, se articulan bajo una serie de violencias simbólicas y en determinadas situaciones también físicas, que demarcan una particular forma de vivir el propio cuerpo en el encierro, a la vez que establecen vasos comunicantes -a modo de ritos de paso o liminalidad- hacia un futuro "comunitas" penal, expresión de los circuitos de gestión para estas poblaciones “problemáticas” en la expansión del estado penal (Wacquant, 2001).

\section{A modo de cierre}

"Al salir de esa celda ya habíamos terminado de entrevistar a todos los jóvenes. Nos dirigimos a la salida del módulo. Nos intercepta de nuevo el subdirector para seguir con el tema de la seguridad. Cuando preguntamos por qué no les daban los colchones ya que eran ignífugos, el subdirector insistió en que largaban monóxido de carbono y que "En el fondo todo esto que hacemos es por ellos (...) "las seguridades son un favor de ellos (...) "las medidas son para que nunca pase nada. Gracias Dios nunca pasó nada, pero porque tomamos precauciones" (Subdirector). Inmediatamente pensé que la neutralización y despojo del cuerpo encerrado es una buena medida que garantiza "que nunca pase nada". En el marco del encierro como un bien y una provisión de amor resulta muy difícil que se crea que en este "hacer el bien" pueda haber límite. A esa altura de la visita noté al subdirector un poco nervioso. Cuando salimos del pabellón dice, nervioso: “Cómo encontraron todo? ¿Todo bien, no?." (Subdirector. Registro de Campo)

Los relatos de campo citados, antes que producir un saber erudito sobre la temática, apuntan a dotar de visibilidad a aquello que es naturalmente opacado: el ejercicio del poder de castigar, que puede ser examinado desde las ciencias sociales en sus propósitos y efectos. Poco se conoce sobre el despliegue "real" del castigo en adolescentes, aunque mucho se discute sobre el mismo. Aun con escasas evidencias empíricas, los debates moldean este despliegue como una "anomalía" susceptible de ser corregida. Lejos de allí, este trabajo apuesta a creer que hay un más allá noanómalo en las formas regulares del ejercicio de la violencia estatal penal, ejercicio normalizado que viola los Derechos Humanos de las personas privadas de libertad. Las apoyaturas morales-correctivas o de mera defensa social que sustentan la privación de la libertad en el caso de los adolescentes, suelen ignorar -a manos de los empresarios morales del orden social- los efectos y funciones de las políticas de control, castigo y segregación. 


\section{S\&e \\ SOCIEDADEEQUIDAD}

Especialmente sobre los adolescentes se procurará, más que "administrar justicia" un desenfrenado "hacer el bien" para protegerlos, habilitando un desmesurado ejercicio del amor punitivo, justificado en las buenas intenciones, que termina por conformar un modelo de lazo punitivo basado en la pedagogía de la subordinación. Este aspecto constituye una limitación para visibilizar la violación a los Derechos Humanos dentro de este tipo de instituciones, que en sus prácticas violentan los Derechos Humanos en general y los del niño en particular, más allá de las "buenas intenciones" de los actores. Aún bajo un profuso discurso sobre los derechos del niño, que se exhiben en la sociedad en general y a través de sus instituciones, este "plus" de derechos que desde la doctrina jurídica penal se confiere a los niños, se topa con un obstáculo infranqueable en el quehacer diario de las instituciones, obstáculo que impide problematizar el castigo como dosificación de dolor, desnudando sus buenas intenciones para exhibir la inversión del principio del "plus" de derechos en una paradójica desventaja: son niños "peligrosos" a cuidar, por lo cual se extreman modalidades institucionales que resultan arrasantes. Así, el dispositivo penal analizado se nutre de recursos estratégicos dotados de un sentido discursivo de protección pero que en sus efectos refrendan el orden de las sociedades excluyentes como devenir natural, bajo el proteccionismo segregativo de neutralización / incapacitación.

Comprender el significado histórico de las nuevas categorías del derecho penal juvenil, cristalizado en agencias judiciales y archipiélagos institucionales de vigilancia, control y castigo, así como de las configuraciones estratégicas, que a modo de relleno o sobredeterminación estructural de los dispositivos da un sentido histórico y sociológico a la privación de libertad, constituye en la actualidad uno de los principales desafíos para la producción de conocimiento crítico y como propuesta para la reconversión de los marcos institucionales y la regulación de la vida en este tipo de dispositivos, acercándolos a modelos dialógicos donde la palabra tenga mayor presencia que la reja. En el caso analizado, las prácticas discursivas intervienen en la elaboración de un espacio con coordenadas a partir de las cuales se constituirá un objeto. Son prácticas que moldean y definen sus sujetos-objetos y cuerpos-objeto no por algún tipo de sustancia que está en su interior sino que desde su exterioridad lo hacen emerger como natural. Hacia la de-construcción de las categorías naturalizadas se han convocado estas reflexiones. 


\section{SSe}

\section{Referencias Bibliográficas}

Bianchi, E. y Portillo, M. (2007). Adolescentes bajo candado: Poder médico, experiencias de encierro y construcción de subjetividad. VII Jornadas de Sociología, FSOC-UBA.

Bourdieu, P. y Wacquant, L. (1995). Respuestas: por una antropología reflexiva. México: Grijalbo.

Bourdieu, P. 1991 (1980). El sentido práctico. Madrid: Taurus.

Bourdieu, P. 1986 (1984). Materiales de sociología crítica. Madrid: La Piqueta.

Bourdieu, P. (1985). ¿Qué significa hablar?. Madrid: Akal.

Clifford J. y Marcus G. (1991). Retóricas de la antropología. Universidad de Barcelona.

Daroqui, A. y Guemureman, S. (2001). "La privación de la libertad en adolescentes y jóvenes: el purgatorio del encierro a la espera de la nada”, en Revista Mayo, Dirección Nacional de Juventud. , v.2, n.1.

De Giorgi, A. (2006). El gobierno de la excedencia. Postfordismo y control de la multitud. Traficantes de sueños. Madrid.

Douglas M. 1988 (1973). Símbolos Naturales. Exploraciones en Cosmología. Madrid: Alianza.

Foucault, M. (1975). Vigilar y Castigar. Buenos Aires: Siglo XXI.

Foucault, M. (1991). La gubernamentalidad, en “Espacios de poder”. Buenos Aires: La Piqueta.

Goffman, E. (1961). Internados. Buenos Aires: Amorrortu.

Le Breton D. (1995). Antropología del cuerpo y modernidad. Buenos Aires: Nueva Visión.

López, A. (2010) .Proceso de Reforma Legal e Institucional del Sistema Penal Juvenil en la Provincia de Buenos Aires (2000-2009. Tesis de Maestría, Fac. Cs. Sociales, UBA. 


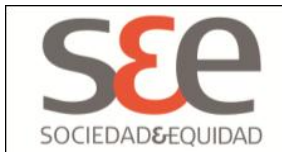

Ortner S. (2005). Geertz, subjetividad y conciencia posmoderna. Etnografías Contemporáneas. UNSM. Escuela de Humanidades. Buenos Aires.

Pavarini, M. (2002) Control y dominación. Teorías criminológicas burguesas y proyecto hegemónico. Buenos Aires: Siglo XXI.

Rusche, G. y Kirchheimer, 0. (1984). Pena y estructura social, $1^{\text {a }}$ edición, Temis, Bogotá

Stake, R. (1999). Investigación en estudio de caso. Madrid: Morata.

Svampa, M. (2006). La sociedad excluyente. La Argentina bajo el signo del neoliberalismo. Buenos Aires: Taurus.

Taylor S. y Bogdan, R. (1986). Introducción a los Métodos Cualitativos de Investigación. Buenos Aires: Paidós.

Wacquant, L. (2001). Las cárceles de la miseria. Buenos Aires: Manantial.

Anexo

Ilustración propia de "habitación"-celda.

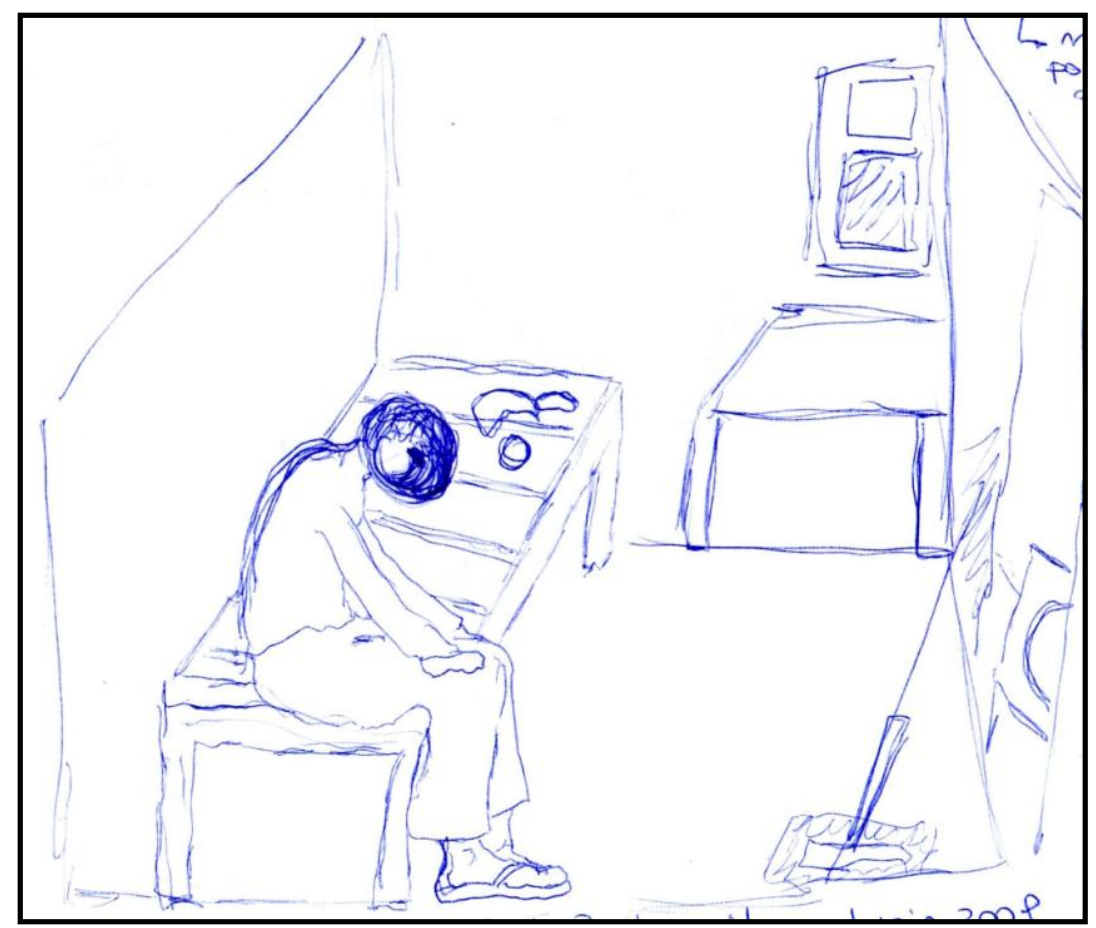

